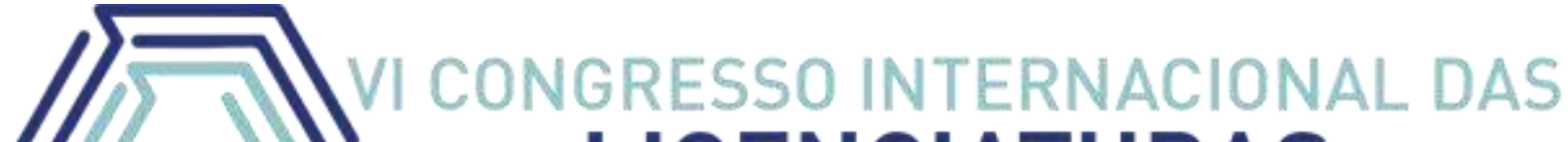 LICENCIATURAS COINTER - PDVL 2019
}

\section{UMA ANÁLISE SOBRE A CONSTRUÇÃO DO CONCEITO DE ENTROPIA A PARTIR DE ABORDAGENS LÚDICAS}

\author{
Apresentação: Comunicação Oral \\ Rita de Cássia Paulo dos Santos ${ }^{1}$; Caio Vasconcelos Pinheiro da Costa ${ }^{2}$; Jardel Lucena da \\ Silva ${ }^{3}$
}

DOI: https://doi.org/10.31692/2358-9728.VICOINTERPDVL.2019.0154

\section{Resumo}

Este trabalho relata uma análise sobre a eficácia da utilização de abordagens de caráter lúdico para a construção do conceito de entropia. Neste contexto, a abordagem lúdica é utilizada através de dinâmicas com jogos, com a finalidade de despertar nos alunos aspectos motivacionais que os permitam participar do processo de ensino-aprendizagem de forma ativa. O conceito de entropia foi escolhido por se tratar de um conceito de difícil apreensão e constituir ainda um tema relativamente pouco explorado na perspectiva do Ensino de Física. Trata-se de um estudo de caso observacional participante, executado nas dependências do campus Santa Cruz do IFRN, com um grupo de 13 alunos do curso de Licenciatura em Física, no qual o docente realizou uma série de 6 intervenções pedagógicas em consonância com o componente curricular Termodinâmica Clássica. A análise dos resultados obtidos nos permite corroborar que este tipo de abordagem pode contribuir de forma positiva para a compreensão de conceitos físicos. No que diz respeito ao conceito de entropia, dentro da perspectiva na qual foi utilizada, julgamos que tal abordagem possibilitou a compreensão do conceito conforme formulado por Ludwig Boltzmann, porém, para que haja um entendimento pleno, percebe-se ainda a necessidade de atividades complementares que estabeleçam o diálogo entre esta interpretação e outras comumente associadas a este conceito, como: desordem, flecha do tempo ou dispêndio de energia. Além desta limitação, verificamos ainda que, mesmo na perspectiva trabalhada, apenas $65,5 \%$ dos alunos mostraram ter adquirido uma compreensão coerente de acordo com o contexto da Física. Ao final, conclui-se que, apesar das limitações constatadas através desta atividade de pesquisa, este trabalho desempenha um papel relevante por fornecer subsídios que permitem fomentar discussões futuras sobre o problema abordado, de modo a enriquecer o panorama vinculado ao Ensino de Física.

Palavras-Chave: Abordagens lúdicas, entropia, Ensino de Física.

\section{Resumen}

\footnotetext{
${ }^{1}$ Licenciatura em Física, IFRN, e-mail: ritinhahesed@hotmail.com

${ }^{2}$ Mestre em Ciências Climáticas, IFRN, e-mail: caio.vasconcelos@ifrn.edu.br

${ }^{3}$ Mestre em Física, IFRN, e-mail: jardel.lucena@ifrn.edu.br
} 
Este artículo informa un análisis de la efectividad del uso de enfoques lúdicos para construir el concepto de entropía. En este contexto, el enfoque lúdico se utiliza a través de dinámicas con juegos para despertar en los estudiantes aspectos motivacionales que les permitan participar activamente en el proceso de enseñanza-aprendizaje. Se eligió el concepto de entropía porque es un concepto difícil de comprender y sigue siendo un tema relativamente poco analizado desde la perspectiva de la enseñanza de la Física. Este es un estudio de caso de observación participante, realizado en el campus de Santa Cruz, en IFRN, con un grupo de 13 estudiantes del curso de Física, en el que el maestro realizó una serie de 6 intervenciones pedagógicas en el componente curricular Termodinámica clásica. El análisis de los resultados nos permite corroborar que este tipo de enfoque puede colaborar positivamente a la adquisición de conceptos físicos. Acerca del concepto de entropía, desde la perspectiva en la que se há utilizado, creemos que este enfoque hizo posible la comprensión de este concepto de acuerdo con la concepción de Ludwig Boltzmann, sin embargo, para comprender completamente, se precisan actividades complementarias que establezcan el diálogo entre esta interpretación y otras comúnmente asociadas con este concepto, como desorden, flecha del tiempo o gasto de energía. Además, se encuentra también que, incluso en la perspectiva trabajada, solamente $65,5 \%$ de los estudiantes mostraron haber adquirido una comprensión coherente del concepto de acuerdo con el contexto de la Física. Al final, se concluye que, a pesar de las limitaciones encuentradas a través de esta actividad de investigación, este trabajo desempeña un papel relevante porque proporciona subsidios que permiten acoger futuras discusiones sobre el problema abordado, con el fin de enriquecer el panorama vinculado a la enseñanza de la Física.

Palabras Clave: Enfoques lúdicos, entropía, enseñanza de la Física.

\begin{abstract}
This paper reports an analysis of the effectiveness of using playful approaches to construct the concept of Entropy. In this context, the playful approach is used through dynamics with games in order to arouse in students motivational aspects that allow them to participate actively in the teaching-learning process. The concept of Entropy was chosen because it is a hard understanding concept and still being a relatively unexplored theme from the perspective of physics education. This is a participant observational case study, developed on the campus of the Santa Cruz, at IFRN, with a group of 13 undergraduate students in Physics, in which the teacher performed a series of 6 pedagogical interventions in line with the curricular component Classical Thermodynamics. The analysis obtained through the data collected during these classes allows us to corroborate that this type of approach can contribute positively to the acquisition of Physical concepts. Regarding the concept of Entropy, from the perspective in which it was used, we believe that such an approach made it possible the understanding of this concept as formulated by Ludwig Boltzmann, but in order to have a full understanding, there is still a need for complementary activities that establish the dialogue between this interpretation and others commonly associated with this concept, such as disorder, time arrow or energy degradation. Besides this limitation, we also found that even in the developed perspective, only $65.5 \%$ of the students showed to have acquired a coherent understanding according to the context of physics. In the end, it is concluded that, despite the limitations found through this research activity, this essay plays a relevant role by providing subsidies that allow foster future discussions on the problem addressed, in order to enrich the landscape linked to the physics education.
\end{abstract}


Keywords: Playful approaches, entropy, physics education.

\section{Introdução}

Vivemos hoje em uma sociedade marcada pela presença da tecnologia no cotidiano dos indivíduos. É inegável o número de vantagens que tais aplicações tecnológicas proporcionam ao bem estar das pessoas, seja na comodidade de acesso e troca de informações, nos transportes, em tratamentos médicos, dentre várias outras possibilidades. Neste contexto, a formação científica das pessoas se apresenta como um fator essencial, tanto para permitir uma inserção mais efetiva destas no meio em que se encontram, como também para fomentar o desenvolvimento de mais aplicações capazes de resolver outros inúmeros problemas que ainda persistem.

No Brasil, a atual situação em que a educação se encontra tem preocupado educadores e a comunidade científica. Os problemas são diversos e os maus resultados podem ser constatados a partir de vários trabalhos especializados em avaliar a qualidade educacional do país (GOLDEMBERG, 1993; MARTINS, 2012). Dentre estes resultados, cabe aqui destacar que a formação de caráter científico tem se mostrado insatisfatória e, neste cenário, percebe-se que a ciência Física, é uma das que mais manifesta problemas (NARDI, 2015).

No que diz respeito à formação atrelada à Física, dentre os muitos problemas existentes está o do ensino-aprendizagem na Educação Básica (BRASIL, 2003) que, apesar de manifestar progressos nas últimas décadas, decorrentes de uma intensificação nas tentativas de diversificação de abordagens, tais como a utilização de História e Filosofia da Ciência, utilização de abordagens experimentais, entre outras, ainda não conseguiu consolidar uma formação científica de qualidade.

Situações como esta obrigam o sistema educacional a encarar como desafio a implantação de ações que englobem o envolvimento dos alunos no ambiente escolar, de modo a apresentar os conteúdos vinculados à Física considerando o seu dia-a-dia e ainda proporcionar a compreensão desta ciência, que desempenha um papel tão importante na história da humanidade (ARAÚJO e ABID, 2003).

Diante deste contexto, no qual a formação científica da população, em geral, tem se mostrado insuficiente, toda pesquisa que se proponha a estudar a eficácia de alguma abordagem metodológica para uma melhor aprendizagem de conceitos e teorias é plenamente justificável. E é justamente nesta perspectiva que o presente trabalho pretende discutir os resultados de uma pesquisa cujo objetivo se pautou em investigar a eficácia da construção de 
conceitos físicos a partir de abordagens de caráter lúdico, através da elaboração e implementação de jogos em sala de aula.

Uma vez que dentro da ciência Física existe uma grande diversidade de temas estudados, é plausível admitir que existem temas melhores compreendidos do que outros. Estudos indicam (BEN-ZVI, 1999; SICHAU, 2000; apud COVOLAN, 2004), por exemplo, que a Termodinâmica, especialmente no que diz respeito ao conceito de entropia e às leis da Termodinâmica, tem se mostrado impopular entre os estudantes e difícil de se trabalhar, devido a uma aparente dissociação entre esses conceitos e o cotidiano dos alunos. Por tal motivo, escolhemos como tema a ser trabalhado através da abordagem lúdica, o conceito de entropia e sua relação com a segunda lei da Termodinâmica.

\section{Fundamentação Teórica}

Ao partirmos do pressuposto de que o processo de ensino-aprendizagem de Física não tem sido suficiente para corroborar uma formação científica de qualidade, não estamos sendo precisos no que diz respeito às possíveis causas correlacionadas à tal constatação. No entanto, dentre as diversas variáveis que podem ser consideradas como candidatas à esta causa, vamos aqui considerar que a motivação dos estudantes pode ser um agente significativamente comprometedor do sucesso deste processo.

Segundo Laburú (2006), a aprendizagem, qualquer que seja, deseja de fato ser ativa, e precisa exigir antecipadamente a precisão da motivação do aprendiz ao que se deve ensinar. Para Bzuneck e Guimarães (2004), a motivação é entendida como um estado psicológico principal que se direciona a uma determinada finalidade; ou seja, é aquilo que faz um sujeito se mobilizar, colocando-o em atuação e podendo fazê-lo mudar de rumo. Neste sentido, faz-se necessário remodelar o ambiente de sala de aula de tal modo que este estado psicológico seja despertado e conduza os discentes a participarem do processo de construção de sua aprendizagem.

Esta mudança de ambiente para despertar a motivação pode ser alcançada pelo uso de convenientes estratégias de ensino, cuja responsabilidade de implantação é do professor (LABURÚ, 2006). Deste modo, afirmam Bzuneck e Guimarães (2004) que o docente pode ter um papel motivacional que favoreça a autonomia, apoiando as necessidades psicológicas básicas de seus alunos e, uma vez estabelecida esta condição, cria-se um espaço em que os alunos possam se interessar pelas tarefas propostas. 
Neste aspecto, afirmam Lourenço e Paiva (2010) que aquele aluno motivado se manifesta de maneira ativa no desenvolvimento da aprendizagem, persistindo em tarefas que o desafiam, esforçando-se, usando táticas adequadas, desenvolvendo assim outras habilidades de compreensão e de domínio.

Neste contexto, acreditamos que a teoria da aprendizagem que melhor subsidia a implementação das condições acima descritas, consiste no construtivismo piagetiano. Para Piaget, a aprendizagem se dá a partir da interação entre o sujeito e o meio. Nesta perspectiva, Piaget considera que a mente do indivíduo tende a funcionar em equilíbrio, aumentando, permanentemente, seu grau de organização interna e de adaptação ao meio; no entanto, quando este equilíbrio é rompido por experiências não assimiláveis, o organismo busca se reestruturar (processo chamado de acomodação), a fim de construir novos esquemas de assimilação (processo que utiliza concepções prévias para compreender as novas situações apresentadas) e atingir novo equilíbrio (MOREIRA, 2014). Este processo de reequilibração é chamado de equilibração majorante, e é tido como fator preponderante na aprendizagem.

As implicações destas proposições se conciliam ao ensino na perspectiva em que este processo passa a ser interpretado como o mecanismo através do qual um desequilíbrio é provocado na mente do sujeito para que ele, procurando o reequilíbrio (equilíbrio majorante), se reestruture cognitivamente e aprenda. É importante ressaltar que em uma situação de sala de aula, o desequilíbrio provocado não deve constituir um obstáculo intransponível aos aprendizes, devendo neste caso, o professor, provocar desequilíbrios de forma gradativa e que sempre permita o desenvolvimento gradual das ideias dos alunos, considerando sempre os esquemas de assimilação destes, o que se deseja ensinar, e os do professor; priorizando ainda abordagens em que sejam dadas aos alunos a oportunidade de agir, desde que tais ações estejam sempre integradas à argumentação, ao discurso, do professor.

Diante desta perspectiva, um recurso que pode se mostrar valioso para a realização desta tarefa consiste na utilização de abordagens de caráter lúdico no processo de ensinoaprendizagem. Segundo Almeida (2009), tal tipo de abordagem, se devidamente utilizada, pode estimular o interesse do aluno, desenvolver níveis diferentes de sua experiência social e pessoal, ajudá-lo a construir suas novas descobertas, desenvolver e enriquecer sua personalidade e, enquanto instrumento pedagógico, pode ajudar o professor a consolidar seu papel de condutor, estimulador e avaliador da aprendizagem.

Ademais, é possível encontrar na literatura acadêmica trabalhos (MELO, G. P. A. N, 2018) que evidenciam que este tipo de abordagem tem se mostrado eficaz neste propósito. Quanto à definições sobre o termo ludicidade na perspectiva de abordagens metodológicas 
vinculadas ao contexto de ensino-aprendizagem, devemos destacar que existem diversas e muitas delas até contraditórias. Segundo Almeida (2009), o lúdico tem sua origem na palavra "ludus", que quer dizer jogo, mas que, no entanto, tal termo já não se restringe ao brincar espontâneo. Para Luckesi (2005), a principal característica da ludicidade é a plenitude da experiência, isto é, a vivência lúdica de uma atividade exige uma entrega total do ser humano.

Apesar desta possibilidade de extrapolação do sentido do lúdico à contextos não necessariamente ligados ao seu sentido original, isto é, vinculados à jogos, devemos levar em consideração que ainda aí residem aspectos básicos aos quais atribuímos as características da ludicidade e, para evidenciarmos isto, basta prestarmos atenção no quão compenetrados e sérios ficam aqueles que se encontram envolvidos em alguma prática de jogos ou brincadeiras.

Neste contexto, acreditamos que abordagens lúdicas podem ser utilizadas como meio modelador do ambiente de ensino-aprendizagem, e que subsidiadas pelo construtivismo piagetiano, pode tornar favorável a predisposição motivacional dos alunos à participação de atividades que os possam levar à compreensão de conceitos de acordo com Ensino de Física.

Sobre o conceito de entropia, podemos afirmar que este é, antes de tudo, complicado! E, devido a sua complexidade, verifica-se que professores tem enfrentado dificuldades no processo de transposição didática deste conceito. Neste contexto, é razoável supor que, tal conceito seja abordado em sala de aula de forma similar ao que é apresentado nos livros didáticos. Segundo Moraes (2011), ainda é muito comum que professores e alunos os tenham como referenciais auxiliadores no processo de ensino-aprendizagem. Neste aspecto, estudos sobre a forma com que tal conceito é abordado em livros didáticos apontam para divergências vinculadas às suas interpretações (HIGO, L. B. et al, 2018), o que contribui substancialmente para perpetuar uma confusão sobre sua compreensão.

Afim de corroborar tal afirmação, vejamos uma breve compilação sobre algumas formas nas quais encontramos o conceito de entropia na literatura acadêmica. Em um dos livros mais utilizados por Físicos, o Thermodynamics and an introduction to thermostatistics de Herbert Callen (1985), o conceito de entropia é introduzido a partir de uma abordagem axiomática na qual a mesma é estabelecida como uma função $S$ de parâmetros extensivos (volume, energia interna e o número de mols) e assume valores máximos quando o sistema termodinâmico se encontra em equilíbrio. Neste sentido, nenhuma interpretação Física sobre o significado da grandeza entropia é estabelecida, sendo esta retomada somente nos últimos tópicos abordados em tal livro.

Por outro lado, em muitos outros materiais didáticos (SEARS E ZEMANSKY, 2009; GASPAR, 2000), o conceito de entropia é introduzido vinculado à segunda lei da 
termodinâmica, na qual se associa inicialmente que a entropia fornece uma medida de um grau de desordem do sistema físico e que qualquer mudança espontânea ocorrida em tal sistema se dá de forma que sua tendência natural é evoluir para um estado que codifique um aumento de sua desordem. Dessa forma, em todo processo natural espontâneo, a entropia do sistema físico tende a aumentar. Além disso, ainda vinculada à segunda lei da termodinâmica, encontram-se complementos de interpretações que afirmam que o aumento da entropia num processo irreversível reflete uma degradação de energia (NUSSENZVEIG, 1990).

Existem também interpretações sobre a entropia e a segunda lei da termodinâmica associadas às ideias de probabilidade, na qual a entropia é compreendida como uma medida da multiplicidade de um sistema físico e que, em um processo termodinâmico, tal sistema evolui para uma configuração em que o estado correspondente ao de equilíbrio é o estado mais provável dentre todos os possíveis (SCHROEDER, 1999). Esta última concepção possibilita ainda outra interpretação, a qual correlaciona a segunda lei da termodinâmica à chamada flecha do tempo, sintetizada na afirmação: “o futuro é a direção em que a entropia tende a aumentar" (NUSSENZVEIG, 1990), e todo fenômeno que ocorre espontaneamente se dá nesta direção, isto é, na direção em que sua entropia aumenta.

Vemos assim, nesta breve compilação, o quanto o conceito de entropia pode ser apresentado de forma diversa. Por tal motivo, acreditamos que esta diversidade pode contribuir para agregar alguma dificuldade em sua compreensão, tanto por parte de alunos, como também por professores em período de formação.

\section{Metodologia}

A metodologia utilizada nesta pesquisa pode ser classificada como qualitativa, por incorporar algumas das características fundamentais desta, como a utilização do ambiente natural como fonte direta de dados, que por sua vez são recolhidos de forma descritiva, visando um interesse maior no processo em detrimento de seus resultados (BOGDAN E BIKLEN, 1994). Quanto ao tipo, ainda segundo Bogdan e Biklen (1994), trata-se de um estudo de caso observacional, sendo esta uma observação participante. Optamos por esta metodologia por a julgarmos adequada ao contexto de uma sala de aula, na qual todo o processo pode ser mediado a partir do professor/pesquisador participante, com o intuito de se evitar uma aquisição de dados irrelevantes no que diz respeito ao problema sob investigação.

Esta pesquisa foi realizada tomando-se como sujeitos 13 alunos de uma turma do curso de Licenciatura em Física do IFRN, no campus Santa Cruz, no decorrer da execução do 
componente curricular Termodinâmica Clássica, no ano de 2019. Para isto, escolhemos um tema pertencente ao currículo do referido componente curricular e organizamos uma oficina pedagógica para trabalhá-lo, de modo a não comprometer o desenvolvimento das atividades por parte do professor. Deste modo, para a execução desta oficina, além dos recursos disponíveis em sala de aula (quadro, pincéis e projetor), utilizamos aplicativos gratuitos para smartphones, que simulavam jogos de dados (Copo de dados) e a escolha de números aleatórios (Aleatório UX), ambos disponíveis no site https://play.google.com/store; um conjunto de moedas confeccionadas de madeira, cujos lados forneciam os valores 0 e 1 ; simuladores disponíveis em páginas da internet, que permitiam uma extrapolação deste jogo, disponível em http://ariehbennaim.com/simulations/index.htm; e uma tábua de Galton, que consiste basicamente de um arranjo de pregos, dispostos em intervalos iguais, atuando como obstáculos à passagem de corpos de prova (pequenas esferas) sob ação da gravidade, que são depositados em canaletas distribuídas em sua parte inferior.

Para o levantamento de informações e acompanhamento destas, utilizamos gravadores de áudio, para permitir uma análise, a posteriori, da evolução das ideais discutidas no decorrer das aulas, sem perdas de informações. E, finalmente, para ajudar a balizar os resultados, aplicamos um questionário avaliativo a ser respondido de forma dissertativa.

Quanto à execução da oficina, a organizamos de modo que a mesma tivesse uma duração de 6 aulas, nas quais estavam previstas as seguintes ações:

Aula 1: Dinâmica com jogos de dados. Nesta aula, utilizamos uma proposta lúdica com o objetivo de desenvolver a noção de probabilidade por parte dos alunos. O jogo foi executado em três etapas, nas quais os alunos deveriam acertar o número proveniente da soma de dados jogados a partir de um aplicativo instalado em um smartphone. Para acentuar o interesse dos alunos a participarem da dinâmica, disponibilizamos como forma de recompensa para os que mais acertassem, prêmios como balas e chocolates. Deste modo, todos os alunos receberam uma planilha na qual registraram suas apostas antes de cada lançamento. Na primeira etapa, ocorreram lançamentos com apenas um dado; na segunda etapa, com dois dados e; na terceira etapa, com três dados. Esperava-se que os alunos percebessem a ocorrência de resultados mais frequentes nas etapas dois e três. Ao final da dinâmica, os alunos foram suscitados a discutir por quais motivos certos resultados apareciam mais do que outros.

Aula 2: Dinâmica com moedas. Nesta aula, seguimos com a proposta lúdica mas, desta vez, através de um jogo com moedas, cujo objetivo principal era induzir os alunos à compreensão da noção de probabilidade condicional. É importante destacar que nosso 
objetivo se restringia a uma compreensão puramente conceitual e instintiva, isto é, não procuramos desenvolver habilidades correlacionadas a cálculos a partir de fórmulas. Devemos ainda ressaltar que esta dinâmica foi inspirada no livro Entropy Demystified (2008), escrito por Arieh Ben-Naim. O jogo consiste em dispor de um conjunto de moedas, confeccionadas

Figura 1- Configurações inicial do jogo com moedas.

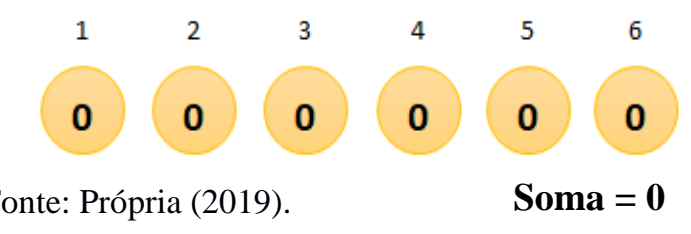

de modo que uma de suas faces possua o valor 0 e a outra o valor 1 . Inicialmente, todas as moedas devem ser dispostas sobre uma mesa com a face 0 voltada para cima:

Uma vez estabelecida esta configuração inicial, cada aluno deve ser convidado a sortear uma destas moedas ao acaso (para isto deve ser utilizado um aplicativo de escolha de números aleatórios em um smartphone, neste exemplo, tal sorteio deveria ser de 1 a 6) e, após este sorteio aleatório, a moeda deve ser flipada. Ao ser flipada, lidamos com duas possibilidades: a moeda fornece o valor 0 ou o valor 1. Este procedimento deve ser repetido várias vezes, digamos 30 vezes, por exemplo. A cada vez que o procedimento é repetido, deve-se avaliar a soma dos valores exibidos por todas as moedas (Verifique o anexo II para ver uma breve simulação deste jogo).

Deste modo, após assegurada a compreensão da dinâmica, cada aluno deve apostar no número que ele acha que corresponderá a soma exibida por todas as moedas e ganhará aquele que acertar o maior número de vezes dentro das rodadas previamente estabelecidas. Tal jogo deverá ser realizado em três etapas: primeiro com 2 moedas (20 vezes), depois com 4 (50 vezes) e, finalmente, com 10 (100 vezes). Observe que o número escolhido pelo aluno deve ser registrado antes do início dos sorteios, ou seja, ninguém poderá mudar o valor apostado uma vez que as moedas comecem a ser flipadas. Para facilitar uma possível interpretação dos resultados por parte dos alunos, o condutor da dinâmica deve construir um gráfico que estabeleça a relação entre o valor da soma a cada jogada e o número destas jogadas.

Deste modo, esperava-se que com o decorrer da dinâmica, os alunos percebessem o padrão que se estabelece com estes resultados. Ao final, os alunos foram incitados a justificar o comportamento do referido padrão.

Aula 3: Dinâmica com muitas moedas através de simuladores. Nesta aula, procuramos estabelecer uma ampliação acerca das concepções adquiridas na intervenção anterior. Este 
objetivo foi delineado para facilitar uma possível analogia entre o comportamento estatístico verificado no jogo com moedas e o comportamento de um sistema termodinâmico. Para isto, utilizamos simuladores deste jogo, desenvolvidos pelo já mencionado autor do livro Entropy Demystified (2008) e disponível também na plataforma já mencionada. A utilização destes simuladores permite que visualizemos o comportamento obtido a partir de uma situação em que se jogue com um número grande de moedas e com um número de lançamentos apreciáveis, que seriam impraticáveis em um ambiente de sala de aula. Esperava-se com isto, que houvesse uma complementação dos resultados desejados na intervenção anterior. Ainda nesta aula, baseados na ideia de que a utilização de materiais manipuláveis pode ampliar as percepções dos alunos acerca do tema trabalhado (MATOS, J. M. e SERRAZINA, M. L, 1996), optamos por utilizar uma tábua de Galton com a intenção de verificar as percepções dos alunos no que diz respeito às suas ideias sobre probabilidade associadas a eventos aleatórios. Neste objeto, os alunos foram convidados a depositar pequenas esferas e adivinhar em qual canaleta tais esferas deveriam cair. Novamente, ao final da dinâmica, os alunos foram suscitados a discutir as causas que favoreciam os resultados obtidos.

Aulas 4 e 5: Transposição das ideias trabalhadas nos jogos para a construção do conceito de entropia. Optamos por descrever estas 2 aulas em um mesmo tópico por entendermos que a metodologia de execução de ambas busca alcançar um mesmo objetivo. $\mathrm{Na}$ aula 4, buscamos retomar alguns conceitos em caráter de revisão breve e estabelecemos uma discussão sobre o processo de expansão livre, modelando-o como um processo quaseestático, no qual era permitido a passagem de uma partícula para a outra câmara somente uma de cada vez e através de uma microporta que se abria brevemente, procurando estabelecer uma analogia entre a evolução do sistema termodinâmico e o comportamento do sistema utilizado nos jogos com moedas. Na aula 5, procuramos evidenciar o conceito de entropia e seu comportamento enquanto grandeza física durante a evolução de um sistema termodinâmico, relacionando-o com a segunda lei da termodinâmica. Desta vez nos restringimos a mediar a discussão de forma expositiva e dialogada, centrada nos recursos usuais tradicionalmente utilizados em sala de aula. Não obstante, buscamos enfatizar a correspondencia direta entre os resultados obtidos nas intervenções anteriores com a compreensão do conceito de entropia, conforme discutido no anexo I.

Aula 6: Atividade avaliativa. Apesar de utilizarmos o método de gravação de áudios durante todo o processo, que por sua vez permite um acompanhamento e sistematização da evolução da aprendizagem sobre o tema trabalhado, optamos por aplicar uma atividade avaliativa com questões acerca dos temas trabalhados, na qual os alunos pudessem refletir e 
sistematizar as ideias discutidas e, simultaneamente, complementar a verificação do objetivo desta pesquisa.

\section{Resultados e Discussão}

Para analisar os dados obtidos conforme métodos descritos no item precedente, vamos adotar a estratégia de Wolcott (apud VALE, 2004), que acomoda esta etapa da pesquisa em três momentos: descrição, análise e interpretação. Como desenvolvemos o trabalho utilizando uma sequência de intervenções, vamos aqui procurar destacar estes três momentos para cada uma delas, embora eventuais resultados comuns a mais de uma intervenção possam ser antecipados ou postergados de acordo com o contexto.

No que diz respeito à primeira aula, pudemos constatar inicialmente que a abordagem de caráter lúdico cumpriu de forma significativa seu objetivo de cativar os alunos a participarem da atividade. Apesar disso, já neste primeiro momento, tivemos de lidar com um problema que se perpetuou durante todas as aulas, que se tratava do não cumprimento de todas as etapas planejadas por falta de tempo. Isto ocorreu pelo fato da dinâmica exigir para sua execução, na prática, um intervalo de tempo maior do que o previsto. Deste modo, reservamos o início da segunda aula para discutirmos aspectos da aula anterior. Através desta discussão, pudemos perceber que os alunos conseguiram compreender de forma satisfatória o fato de que existiam configurações mais prováveis do que outras e, devido a tal percepção, os mesmos apostavam com mais frequência nos números associados a estas configurações.

Ainda na aula 2, colocamos em prática o jogo das moedas conforme planejado, executando-o em três etapas, com 2, 4 e 10 moedas, respectivamente. Os resultados (dos jogos) foram expostos no quadro através de um gráfico e, com isso, distribuímos os brindes para os participantes, nos mesmos moldes que na atividade da aula 1.

No terceiro encontro, os alunos foram confrontados com os resultados descritos através dos gráficos realizados na intervenção anterior, sendo suscitados a identificar os padrões estabelecidos e procurar justificá-los. A seguir, exibimos uma das configurações exploradas neste momento.

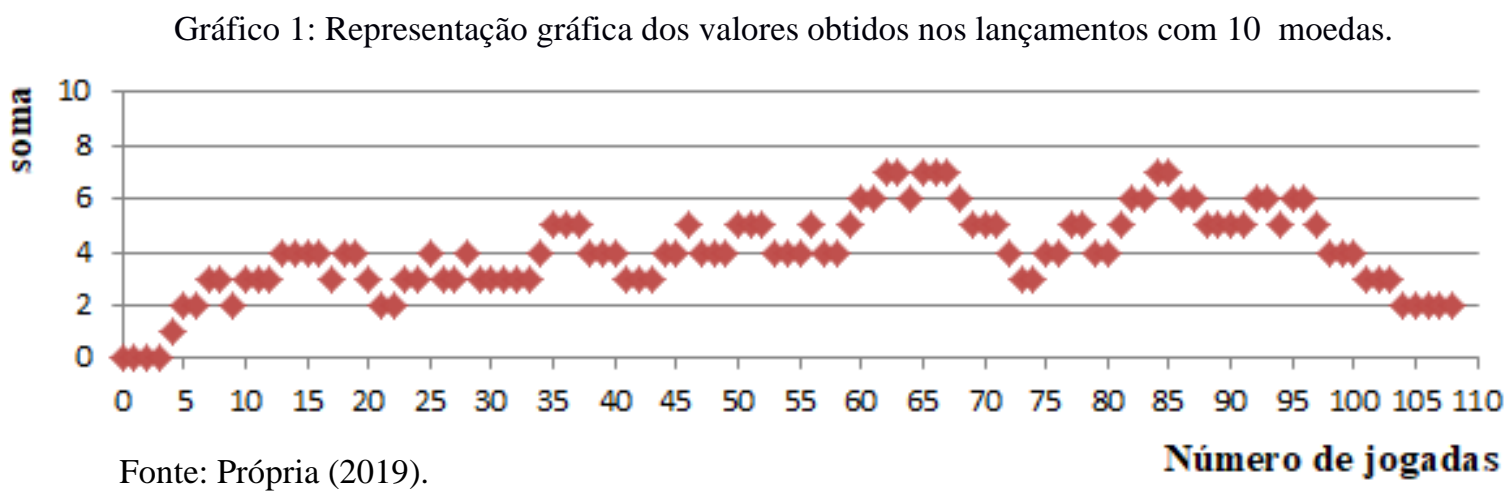


Perceba que o padrão aqui estabelecido nos mostra que o sistema caracterizado pela soma dos valores das moedas assume uma tendência de crescimento até que seja atingido um valor em torno do qual tende a flutuar, correspondente à metade da soma máxima.

A partir de discussões conduzidas pelo professor, os alunos puderam justificar de forma adequada o comportamento observado nos resultados, condizente com as ideias discutidas no Anexo II. É importante ressaltar que as conclusões acerca das probabilidades condicionais vinculadas ao padrão dos resultados foi alcançado sem que o professor o tenha explicitado de forma direta. No entanto, houve participação do docente na perspectiva de formular perguntas que ajudassem os alunos a chegar a tais conclusões.

Após os momentos de discussões, iniciamos as atividades planejadas para a aula 3 conforme exposto na metodologia. A partir da utilização dos simuladores não foi constatada nenhuma novidade nas interpretações por parte dos alunos, a não ser o fato de que as flutuações em torno do valor de equilíbrio pareciam ser menores do que no caso discutido anteriormente, conforme podemos verificar através de um dos gráficos obtidos no simulador, para o caso de 50 moedas e 500 jogadas (Gráfico 2).

Gráfico 2: Representação gráfica dos valores obtidos no lançamento com 50 moedas.

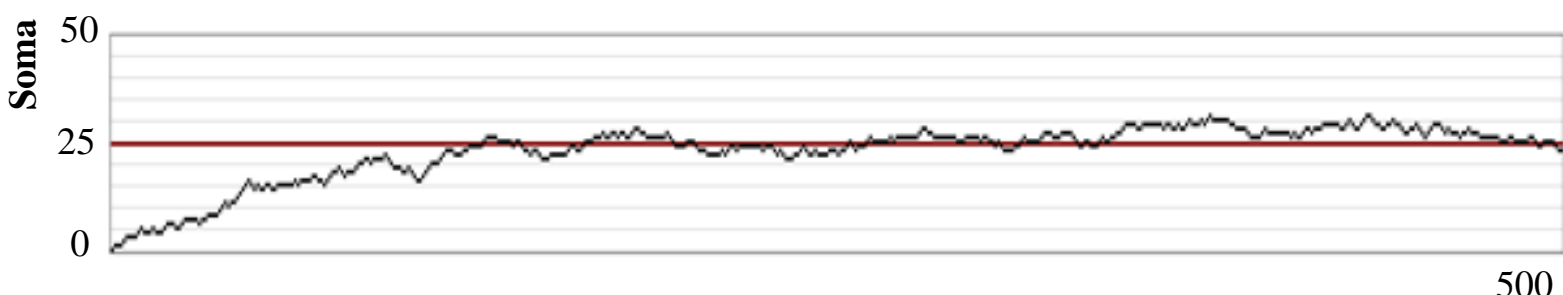

Número de jogadas

Fonte: Adaptada de http://ariehbennaim.com/simulations/index.htm (2019)

Logo após tais discussões, aplicamos a dinâmica com a tábua de Galton. Ao executarmos a tarefa proposta descrita na metodologia, os alunos manifestaram dificuldades em estabelecer percepções de semelhanças entre os eventos da tábua de Galton e o jogo das moedas. A maioria dos alunos apostaram que as esferas cairiam nas canaletas mais próximas às extremidades ao invés das que se localizavam na região central. Após verificarem a distribuição que se formou depois que um número relevante de esferas foi utilizado, constataram que existia uma tendência mais favorável à ocupação das canaletas centrais, mas ainda assim, não conseguiram formular uma explicação coerente para tal fato. Neste caso, para que a compreensão fosse alcançada, foi necessário ao docente recorrer à ilustrações com modelos de Tábuas de Galton mais simples e, a partir delas, evidenciar que o número de caminhos que levam às configurações centrais é maior e, como todos os caminhos são 
equiprováveis, tais configurações são favorecidas. Neste caso, concluímos que o objetivo foi parcialmente alcançado, pois os alunos foram bem sucedidos sobre a culminância das ideias sobre o jogo das moedas mas, por outro lado, não o foram em adquirir a mesma percepção através da tábua de Galton.

Ao colocarmos em prática o planejamento realizado para as aulas 4 e 5, pudemos logo evidenciar uma retomada da postura dos alunos ao modo tradicional ocorrido nas aulas, isto é, desta vez não presenciamos o envolvimento e entrega à participação da aula como se deu nas intervenções anteriores. Apesar disso, ao buscarmos estabelecer uma correspondência entre os resultados de percepções obtidas a partir dos jogos e a evolução do sistema termodinâmico, constatamos alguns resultados satisfatórios.

Foi constatado que ao analisar a evolução do sistema termodinâmico, os alunos perceberam que, no mesmo, havia um comportamento semelhante a algo dos jogos, isto é, que havia algo inerente ao sistema que aumentava até a situação em que tal sistema alcançava o estado de equilíbrio. Quando incitados a explicar o que era este "algo", alguns mencionaram que era a entropia. E, quando indagados sobre o que era entropia e por qual motivo ela aumentava no decorrer do processo termodinâmico, obtivemos respostas do tipo: "é a desordem”, “é a desordem do sistema que aumenta”. Obviamente, esta noção de Entropia já fazia parte das concepções prévias de alguns alunos, que naturalmente possuíam vínculos com o contexto acadêmico através do curso de Licenciatura em Física. No entanto, tais alunos não estabeleceram nenhuma relação entre suas percepções do conceito de entropia e o caráter probabilístico evidenciado nas atividades lúdicas.

Com o intuito de promover uma compreensão mais fundamentada do conceito de entropia, o professor desenvolveu uma série de explicações baseadas no comportamento de um sistema termodinâmico no estado gasoso constituído por 4 partículas, conforme pode ser verificado no Anexo I. No decorrer desta discussão, os alunos foram solicitados a escolher qual das configurações possíveis corresponderia a uma situação de equilíbrio termodinâmico após um processo de expansão livre e questionados sobre as razões pelas quais a evolução do estado do sistema termodinâmico se dava daquela forma. Apenas a partir deste ponto que os alunos estabeleceram uma relação direta entre o comportamento do sistema termodinâmico e o caráter probabilístico evidenciado em processos espontâneos. Uma vez estabelecida esta conexão, o professor introduziu a nomenclatura utilizada na literatura científica para denotar os fenômenos físicos até então estudados, com o intuito de acomodar a compreensão dos alunos ao contexto da Física.

A partir de dados recolhidos através da atividade avaliativa aplicada na aula 6 , 
pudemos constatar que 65,5\% do grupo conseguiram compreender o conceito de entropia dentro da perspectiva pretendida, isto é, de forma condizente com a interpretação de Ludwig Boltzmann, em consonância com a exposição descrita no Anexo I.

Diante da análise realizada neste estudo de caso, podemos afirmar que a abordagem lúdica cumpriu de forma satisfatória o objetivo de cativar os alunos para o processo de ensinoaprendizagem. No que se refere aos jogos utilizados especificamente para a realização desta pesquisa, ressaltamos que, apesar de aspectos positivos vinculados a possibilidade de se construir a percepção de eventos condicionados por fatores de caráter probabilístico, ambos os jogos se mostraram exaustivos devido ao grande número de repetições. Isto pode ser considerado um problema relevante pelo fato de que o comportamento desejável manifestado pelos resultados dos jogos só se evidencia de forma clara justamente na situação que envolva um grande número de jogadas. Apesar disto, acreditamos que a abordagem escolhida para desenvolver o conceito de entropia pode ser considerado um recurso válido, uma vez que, diante de sua complexidade, ainda assim se mostrou eficaz, mesmo que não plenamente.

Destacamos ainda o fato de que, apesar da constatação da eficiência da abordagem, faz-se necessário o desenvolvimento de atividades complementares que permitam aos alunos desenvolver percepções que relacionem a interpretação esboçada neste trabalho com outras comumente presentes na literatura acadêmica, como vinculadas às ideias de desordem, flecha do tempo e degradação da energia, além da devida operacionalização matemática do conceito e aplicabilidade do mesmo em situações do cotidiano.

Deste modo, a abordagem utilizada pode ser considerada útil para desenvolver uma compreensão inicial do conceito de entropia; no entanto, para uma compreensão plena, outros recursos devem ser considerados, além dos realçados neste trabalho.

\section{Conclusões}

A partir da atividade de pesquisa relatada através deste trabalho podemos concluir que, de fato, a abordagem lúdica pode desempenhar um papel relevante na construção de conceitos físicos, tanto do ponto de vista motivacional, ao cativar o interesse de participação dos alunos nas aulas, mas, também, pelo poder de estabelecer correspondências e analogias condizentes com as características dos conceitos físicos.

A percepção proporcionada a partir dos resultados expostos nos mostra que o conceito de entropia foi compreendido de forma satisfatória pela maioria dos sujeitos participantes da pesquisa e que, embora tal compreensão não tenha acontecido de forma plena, devido, 
principalmente, à complexidade do conceito abordado, pudemos obter subsídios para realizar estudos complementares que permitirão abordar o referido problema considerando-se variáveis anteriormente não previstas.

Deste modo, destacamos que fazem-se necessárias avaliar novas perspectivas para o refino da presente pesquisa. Não obstante, espera-se que as propostas e discussões aqui relatadas possam ser utilizadas como ponto de partida para realização de novos estudos, com vista a enriquecer o panorama do Ensino de Física e, mais particularmente, do ensino do conceito de entropia.

\section{Referências}

ALMEIDA, Anne. Ludicidade como instrumento pedagógico. Cooperativa do Fitness, Belo Horizonte, jan. 2009. Seção Publicação de Trabalhos. Disponível em http:www.cdof.com.br/recrea22.htm.

ARAÚJO, M. S. T.; ABID, M. L. V. S. Atividades experimentais no ensino de Física: Diferentes enfoques, diferentes finalidades. Revista Brasileira de Ensino de Física, v. 25. n. 2. p. 176-194, 2003.

BEN-NAIM, A. Entropy demystified: the second law reduced to plain common sense. Singapore: World /scientific. 2008.

BOGDAN, R. C.; BIKLEN, S. K. Investigação qualitativa em educação: uma introdução à teoria e aos métodos. Portugal: Porto Editora, 1994.

BRASIL. Diretrizes Curriculares de Física para a Educação Básica. Secretaria de Educação do Paraná. Curitiba: 2006.

BZUNECK, J. A.; GUIMARAES, S. E. R. Aprendizagem escolar em contextos competitivos. Em BORUCHOVITCH, E. \& BZUNECK, J. A (Orgs). Aprendizagem: processos psicológicos e o contexto social. $1^{\mathrm{a}}$ ed. Petrópolis RJ: Ed. Vozes Ltda., 2004, v.1, p 251-277.

CALLEN, H. Thermodynamics and an Introduction to Thermostatistics. John Wiley and Sons, Inc. $2^{\mathrm{a}}$ ed. New York.1985.

COVOLAN, S. C. T. O conceito de entropia num curso destinado ao ensino médio a partir de concepções prévias dos estudantes e da história da ciência. 2004. 112 p. Dissertação Mestrado. Faculdade de Educação, Universidade Estadual de Campinas, Campinas, 2004.

GASPAR, Alberto. Física. Vol. 2- São Paulo: Ática, 2000.

GOLDEMBERG, José. (1993). O repensar da educação no Brasil. Estudos Avançados, 7(18), 65-137. https://dx.doi.org/10.1590/S0103-40141993000200004. 
HIGO, L. B. et al. As muitas interpretações da entropia e a criação de um material didático para o ensino da interpretação probabilística da entropia. Quím. nova esc. - São Paulo-SP, BR. Vol. 40, № 3, p. 169-177, AGOSTO 2018.

LABURÚ, C. E.; CARVALHO, M. Educação científica: controvérsias construtivistas e pluralismo metodológico. Londrina: Eduel, 2005.

LOURENÇO, A. A.; PAIVA, M. O. DE. A motivação e o processo de aprendizagem. Ciências \& Cognição; Vol. 15 (2): 132-141. Portugal: 2010.

LUCKESI, Cipriano Carlos. Ludicidade e Atividades Lúdicas: uma abordagem a partir de experiências internas. Disponível em: <www.luckesi.com.br>. Acesso em: 15 abr. 2019.

MARTINS, EBC. Educação e serviço social: elo para a construção da cidadania. São Paulo: Editora UNESP. 2012. A política de educação brasileira: uma leitura sob a óptica do serviço social. pp. 75-113. ISBN 978-85-3930-243-7. Available from SciELO Books.

MATOS, J. M.; SERRAZINA, M. de L. Didática da Matemática. Universidade Aberta: Lisboa, 1996.

MELO, G. P. A. N. A ludicidade como um recurso pedagógico na educação infantil. Caderno de Produção Acadêmico-Científica. Programa de Pós-Graduação em Educação, Vitória ES. V. 24, n. 1. 29-43p. Jan./jun. 2018.

MORAES, J.U.P. O Livro Didático de Física e o Ensino de Física: suas relações e origens. Scientia Plena, vol.7, Num. 9, 2011.

MOREIRA, M. A. Teorias de aprendizagem. 2. Ed. Ampl. São Paulo: E. P. U. 2014

NARDI, Roberto. A pesquisa em ensino de Ciências e Matemática no Brasil. Bauru. Vol 21. N.2.I-V p. Jun. 2015.

NUSSEnZVEIG, H. Moysés. Curso de Física Básica. Volume 2. Fluídos, Oscilações e Ondas, Calor. $2^{a}$ ed. São Paulo: Editora Edgard Blucher Ltda.1990.

SCHROEDER, Daniel V. An introduction to Thermal Physics. Addison-Wesley Longman, 1999.

SEARS, F. W. ZEMANSKY, M. W.; YOUNG, Hugh D.; FREEDMAN, Roger A. Física II: Ondas e termodinâmica. 12. ed. São Paulo, SP: Pearson Addison Wesley, c2008-2009 vol 4.

VALE, Isabel. Algumas notas sobre Investigação Qualitativa em Educação Matemática, O Estudo de Caso. Revista da Escola Superior de Educação, vol.5. Escola Superior de Educação de Viana do Castelo, p.171-202, 2004.

\section{Anexo I}

Ao leitor que não esteja familiarizado com o conceito de entropia e suas interpretações, esboçamos neste anexo um breve desenvolvimento do respectivo conceito com fins à 
subsidiar a discussão dos resultados. Ressaltamos, porém, que um desenvolvimento rigoroso de tal conceito extrapola a intenção deste trabalho e nos restringimos a utilizar a concepção de entropia que nos parece mais adequada no que diz respeito à sua compreensão. Por isto, optamos por trabalhar tal conceito através de um viés estatístico, conforme a interpretação de Boltzmann, estabelecida por volta de 1866.

Neste contexto, afinal, o que é entropia? Para estabelecermos uma interpretação consistente, precisamos levar em consideração o conhecimento do sistema termodinâmico do ponto de vista microscópico. Deste modo, considere um sistema termodinâmico simples (gás) composto por 4 partículas que, inicialmente, ocupam um dos dois compartimentos de uma câmara isolada (conforme ilustrado na figura 2), rotulada por configuração 1.

Figura 2- Configurações indistintas e específicas do sistema termodinâmico

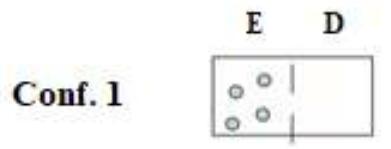

Conf. 2

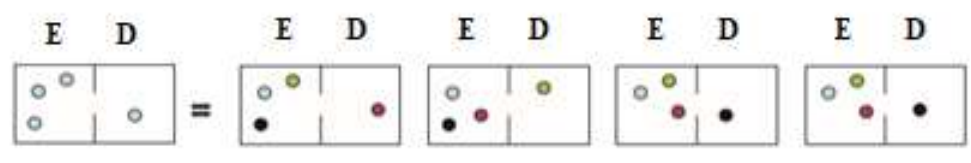

Conf. 3
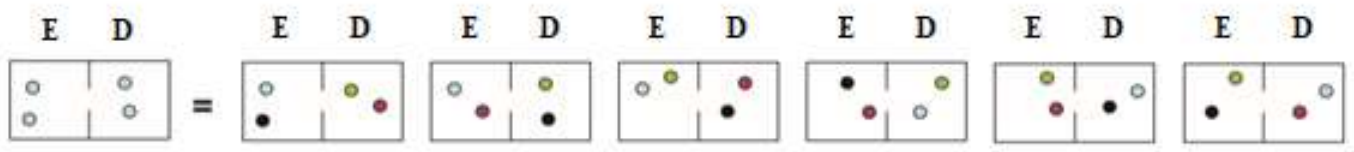

Conf. 4

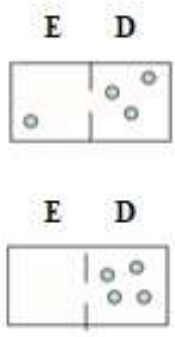

Conf. 5

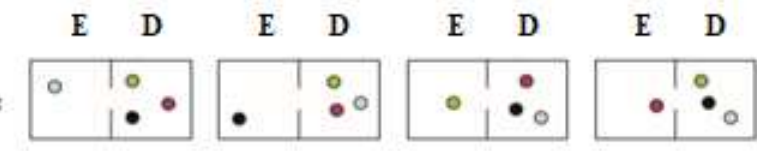

Fonte: Adaptada de Entropy Demystified (2008).

Neste caso, dizemos que a configuração corresponde a um estado do sistema termodinâmico, caracterizado por possuir 4 partículas na câmara esquerda e nenhuma na direita. Referirmo-nos a esta configuração como (E4:D0) [leia-se: Esquerda 4 e Direita 0].

Por outro lado, suponhamos que uma partícula migre para o lado direto da câmara, definindo um novo estado caracterizado agora por possuir 3 partículas na câmara esquerda e 1 na câmara direita, estabelecendo a configuração 2: (E3 :D1). Perceba que, numa situação em que fosse possível diferenciar as 4 partículas [todas com cores distintas], haveriam 4 configurações possíveis correspondentes ao referido estado, no qual conheceríamos 
exatamente qual partícula se encontra na câmara direita. Neste caso, nos referiremos a este tipo de configuração como configuração específica ou microestado. Por outro lado, na situação em que não seja possível especificar exatamente quais partículas se encontram em cada câmara, vamos denotar tal configuração como configuração indistinta ou macroestado.

Já na configuração 3, (E2:D2), existem 6 configurações específicas correspondentes à sua configuração indistinta; as demais configurações seguem o mesmo princípio. Deste modo, podemos constatar que, para cada macroestado em que o sistema termodinâmico se encontra, existe sempre um certo número de microestados. A este número de microestados correspondentes a um certo macroestado, chamamos de multiplicidade. No nosso exemplo, temos que a configuração 4 possui multiplicidade igual a 4 , pelo fato de existirem 4 microestados correspondentes ao macroestado ( $E 1: D 3)$.

Mas, afinal, qual a relação disso com o conceito de entropia? Considere que um sistema termodinâmico sofrerá um processo de natureza espontânea, levando-o de um estado inicial qualquer para outro estado posterior no qual se estabelece a condição de equilíbrio termodinâmico. É um fato experimental que, se tal sistema termodinâmico for composto por um número muito grande de partículas (caso de sistemas termodinâmicos reais), o estado de equilíbrio corresponderá "sempre" ao estado de maior multiplicidade. Estabelece-se aqui uma correspondência entre multiplicidade e entropia!

Evidentemente, esta correspondência se deu de forma mais rigorosa a partir do desenvolvimento efetuado por Boltzmann, no qual é possível mostrar que a segunda lei da termodinâmica pode ser fundamentada apenas a partir da teoria das probabilidades (MAGIE, 1935, apud COVOLAN, 2004). Deste modo, a relação entre multiplicidade e entropia é descrita pela equação: $S=\kappa \ln \Omega$, onde $S$ denota a entropia, $\Omega$ a multiplicidade correspondente a um determinado estado e $\kappa$ a constante de Boltzmann.

Segundo Schroeder (1999), se quisermos compreender o significado da entropia vinculado à esta equação, devemos ignorar o fator da constante de Boltzmann e admitir que a entropia é simplesmente $\ln \Omega$, onde a função logarítimo natural pode ser interpretada como um fator conveniente para se lidar com números muito grandes.

Deste modo, podemos interpretar que se, em um processo termodinâmico que ocorra espontaneamente, a entropia de um sistema aumenta de modo que alcança seu valor máximo no estado de equilíbrio, é equivalente a afirmar que, em um processo espontâneo, tal sistema evolui de modo a assumir o estado correspondente a configuração mais provável, ou seja, a de maior multiplicidade. 


\section{Anexo II}

Vejamos uma breve demonstração para assegurar a compreensão do objetivo a ser alcançado com este jogo. Consideremos que partimos da configuração inicial, que seja aleatoriamente sorteada a moeda 4 e que, logo após, esta seja flipada e forneça o resultado 1. Deste modo, a nova configuração apresentada deve ser:

Figura 3 - Possível configuração obtida na primeira rodada de simulação do jogo com moedas.

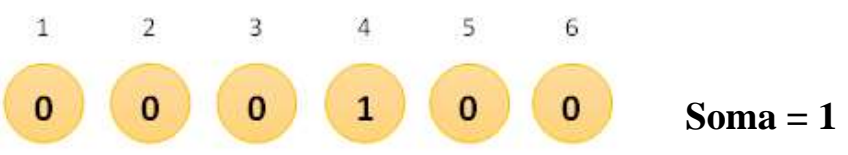

Fonte: Própria (2019).

Neste caso, vencerá quem apostou na soma total 1. No entanto, devemos nos atentar para os valores possíveis da próxima soma. Perceba que agora temos 5 possibilidades de sortearmos uma moeda com valor 0 e apenas 1 possibilidade de sortear a moeda de valor 1 . Vamos avaliar o caso em que sorteamos uma moeda com valor 0 , que é o evento mais provável, digamos a moeda 2 . Neste caso, quando a moeda é flipada, podemos obter as possíveis configurações:

Figura 4- Possíveis configurações obtidas na segunda rodada no jogo com moedas.

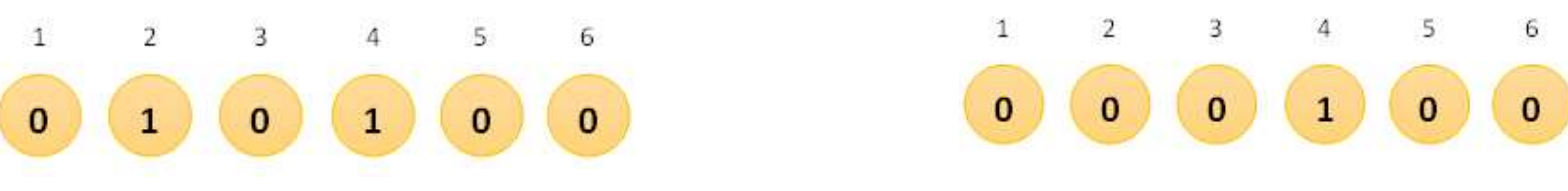

Fonte: Própria (2019).

Soma $=2$

Soma $=1$

Por outro lado, acaso a moeda 4 seja sorteada, que consiste no evento menos provável, podemos obter as seguintes configurações:

Figura 5- Outras possíveis configurações obtidas na segunda rodada no jogo com moedas.

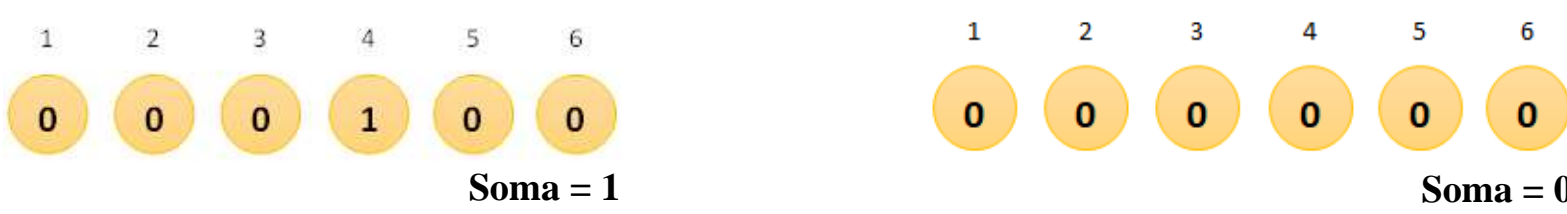

Fonte: Própria (2019).

Com isto, podemos evidenciar que, em uma eventual mudança da configuração de soma $=\mathbf{1}$, é bem mais provável que tal mudança ocorra para a configuração soma $=\mathbf{2}$, de modo que, inicialmente, os valores da soma tendem a assumir valores cada vez maiores. No entanto, esta tendência de aumento da soma ocorre somente no início. Isto porque, numa 
sequência de eventos aleatórios, a configuração evolui naturalmente para uma configuração na qual se estabelece um tipo de equilíbrio.

Para compreender isto, considere a configuração soma $=\mathbf{3}$, como a exposta a seguir:

Figura 6 - Configuração de equilíbrio no jogo com moedas.

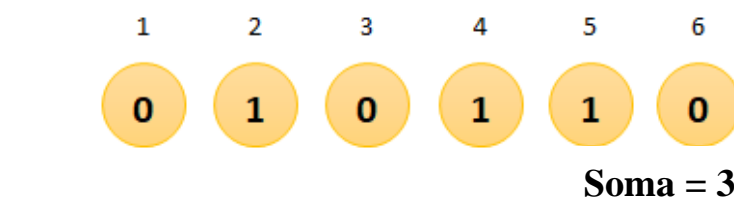

Fonte: Própria (2019).

Perceba que nesta configuração, ao sortearmos uma moeda aleatória, encontramos a mesma probabilidade de acertarmos uma moeda de valor 1 ou 0 . E, consequentemente, a probabilidade do valor da soma aumentar é igual ao da soma diminuir.

Por outro lado, considere que, em um evento aleatório sobre a configuração soma $=\mathbf{3}$, a moeda sorteada tenha sido a primeira e, uma vez flipada, esta tenha fornecido o valor 1 , levando a configuração a evoluir para soma $=\mathbf{4}$.

Figura 7 - Configuração de soma 4 no jogo com moedas.

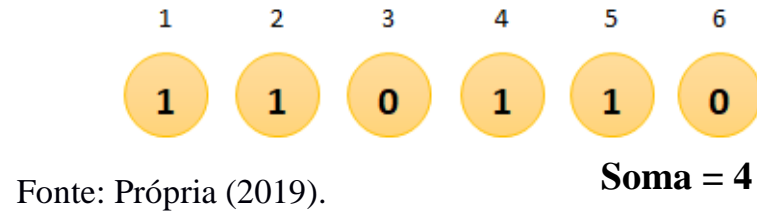

Perceba que, neste caso, no próximo evento aleatório da escolha da moeda, é mais provável que seja sorteada uma moeda de valor $1 \mathrm{em}$ detrimento do valor 0 . E, sendo este o caso, temos que existem duas possibilidades: ou a configuração se mantem soma $=\mathbf{4}$, caso em que a moeda flipada forneça o valor 1 , ou a configuração evolui para soma $=\mathbf{3}$, acaso a moeda flipada forneça o valor 0 . Ou seja, se houver alguma mudança na configuração, é mais provável que esta aconteça no sentido de atingir a configuração soma = $\mathbf{3}$.

Deste modo, podemos perceber que existe um padrão no comportamento dos resultados possíveis vinculados à soma fornecida pelas moedas. Ao partirmos da configuração soma $=\mathbf{0}$, temos uma tendência de aumento até que seja atingida a configuração soma $=\mathbf{3}$ e qualquer mudança desta configuração para outra favorecerá, num próximo evento aleatório, o retorno para esta mesma configuração, fato este que justifica a convenção de chamá-la de configuração de equilíbrio. Este comportamento será melhor evidenciado quanto maior for o número de moedas utilizadas e o número de rodadas em que estas sejam flipadas. 